\title{
Investment in Stock Market: Fundamental and Technical Analysis
}

\author{
C. Murugesan ${ }^{1}$, E. Sakthi Priya ${ }^{2}$ \\ ${ }^{1,2}$ Senior Lecturer, Institute of Business Studies, Port Moresby, Papua New Guinea.
}

\begin{abstract}
Investment openings are plenty, but not all are profitable. This article seeks to clarify the need to make a proper fundamental analysis when investing in various securities. Fundamental analysis does not require one to be a financial analyst so as to detect high risk assets or assets with a good return in the future. Traders typically approach financial markets in one of two ways: either through technical analysis or fundamental analysis. Technical analysis uses historical stock statistics, usually price and volume data, to forecast future prices, while fundamental analysis tries to predict a stock's intrinsic, or 'fundamental' value, and looks for opportunities where the live price deviates from the calculated intrinsic price. Well-organized investment involves the use of both fundamental analysis and technical analysis.
\end{abstract}

Keywords: Investment, Fundamental Analysis, Technical Analysis, Risk, Returns

\section{Introduction}

Fundamental analysis is the examination of the underlying forces that affect the well-being of the economy, industry groups and companies. As with most analysis, the goal is to develop a forecast of future price movement and profit from it. At the company level, fundamental analysis may involve examination of financial data, management, business concept and competition. At the industry level, there might be an examination of supply and demand forces of the products.

For the national economy, fundamental analysis might focus on economic data to assess the present and future growth of the economy. To forecast future stock prices, fundamental analysis combines economic, industry, and company analysis to derive a stockees fair value called intrinsic value. If fair value is not equal to the current stock price, fundamental analysts believe that the stock is either over or under valued. As the current market price will ultimately gravitate towards fair value, the fair value should be estimated to decide whether to buy the security or not. By believing that prices do not accurately reflect all available information, fundamental analysts look to capitalize on perceived price discrepancies.

Fundamental Analysis is a method of evaluating a security by attempting to measure its intrinsic value by examining related economic, financial and other qualitative and quantitative factors. Fundamental analysts attempt to study everything that can affect the securityes value, including macroeconomic factors and individual specific factors.

\section{Objectives of Fundamental Analysis}

1) Make financial forecasts.

2) Conduct a company stock valuation and predict price evolution.

3) Evaluate and predict business performance.

4) Calculate a company ${ }^{\text {ee }}$ s credit risk.

5) Evaluate company management and make internal business decisions.
Here the financial analyst first makes forecasts for the economy, then for industries and finally for companies. The industry forecasts are based on the forecasts for the economy and in turn, the company forecasts are based on the forecasts for both the industry and the economy. Also in this approach, industry groups are compared against other industry groups and companies against other companies. Usually, companies are compared with others in the same group. For example, a cement company would be compared to another cement company not to a steel company.

Thus, the fundamental analysis is a three level analysis of

a) The economy

b) The industry and

c) The company

\section{Advantages of Fundamental Analysis}

Fundamental analysis have advantages to the investor in decision making. The advantages include;

Objectivity: Fundamental analysis makes use of sound mathematical and statistical principles to produce ratios so that there is no room for personal bias.

Long term focus: Markets are usually driven by fundamental factors over the long term, and hence developing a trend. Fundamental analysis can look at longterm economic, demographic, technologic or consumer trends.

Value: By determining an intrinsic value, fundamental analysts can determine appropriate buy prices that represent 'good value'.

Increased understanding: Research into fundamentals provides the investor with a better understanding of the company and its business.

Sleep at night factor: Investors know that they are investing in fundamentally sound companies because they have done their 'due diligence' analysis. 


\section{International Journal of Science and Research (IJSR) \\ ISSN (Online): 2319-7064}

Index Copernicus Value (2013): 6.14 | Impact Factor (2014): 5.611

\section{Technical Analysis}

Fundamental analysis and Technical analysis are the two main approaches to security analysis. Technical analysis is frequently used as a supplement to fundamental analysis rather than as a substitute to it. According to technical analysis, the price of stock depends on demand and supply in the market place. It has little correlation with the intrinsic value. All financial data and market information of a given stock is already reflected in its market price.

Technical analysts have developed tools and techniques to study past patterns and predict future price. Technical analysis is basically the study of the markets only. Technical analysts study the technical characteristics which may be expected at market turning points and their objective assessment. The previous turning points are studied with a view to develop some characteristics that would help in identification of major market tops and bottoms. Human reactions are, by and large consistent in similar though not identical reaction; with his various tools, the technician attempts to correctly catch changes in trend and take advantage of them.

Technical analysis is directed towards predicting the price of a security. The price at which a buyer and seller settle a deal is considered to be the one precise figure which synthesis, weigh sand finally expresses all factors, rational and irrational, quantifiable and non-quantifiable and is the only figure that counts.

Thus, the technical analysis provides a simplified and comprehensive picture of what is happening to the price of a security. Like a shadow or reflection it shows the broad outline of the whole situation and it actually works in practice.

\section{Assumptions of Technical Analysis}

- The market value of a security is solely determined by the interaction of demand and supplyfactors operating in the market.

- The demand and supply factors of a security are surrounded by numerous factors; these factors are both rational as well as irrational.

- The security prices move in trends or waves which can be both upward or downward depending upon the sentiments, psychology and emotions of operators or traders.

- The present trends are influenced by the past trends and the projection of future trends is possible by an analysis of past price trends.

- Except minor variations, stock prices tend to move in trends which continue to persist for an appreciable length of time.

- Changes in trends in stock prices are caused whenever there is a shift in the demand and supply factors.

- Shifts in demand and supply, no matter when and why they occur, can be detected through charts prepared specially to how market action.

- Some chart trends tend to repeat themselves. Patterns which are projected by charts record price movements and these patterns are used by technical analysis for making forecasts about the future patterns.

\section{Tools and Techniques of Technical Analysis}

There are numerous tools and techniques for doing technical analysis. Basically this analysis is done from the following four important points of view:-

Prices: Whenever there is change in prices of securities, it is reflected in the changes in investor attitude and demand and supply of securities.

Time: The degree of movement in price is a function of time. The longer it takes for a reversal in trend, greater will be the price change that follows.

Volume: The intensity of price changes is reflected in the volume of transactions that accompany the change. If an increase in price is accompanied by a small change in transactions, it implies that the change is not strong enough.

Width: The quality of price change is measured by determining whether a change in trend spreads across most sectors and industries or is concentrated in few securities only. Study of the width of the market indicates the extent to which price changes have taken place in the market in accordance with a certain overall trends.

\section{Dow Theory}

The Dow Theory, originally proposed by Charles Dow in 1900 is one of the oldest technical methods still widely followed. The basic principles of technical analysis originate from this theory. According to Charles Dow "The market is always considered as having three movements, all going at the same time. The first is the narrow movement from day to day. The second is the short swing, running from two weeks to a month or more and the third is the main movement, covering at least four years in its duration".

The Theory advocates that stock behaviour is $90 \%$ psychological and 10\% logical. It is the mood of the Crowd which determines the way in which prices move and the move can be gauged by analyzing the price and volume of transactions.

The Dow Theory only describes the direction of market trends and does not attempt to forecast future movements or estimate either the duration or the size of such market trends. The theory uses the behaviour of the stock market as a barometer of business conditions rather than as a basis for forecasting stock prices themselves. It is assumed that most of the stocks follow the underlying market trend, most of the times.

A trend should be assumed to continue in effect until such time as its reversal has been definitely signaled. The end of a bull market is signalled when a secondary reaction of decline carries prices lower than the level recorded during the earlier reaction and the subsequent advance fails to carry prices above the top level of the preceding recovery. The end of a bear market is signalled when an intermediate

\section{Volume 5 Issue 2, February 2016}




\section{International Journal of Science and Research (IJSR) \\ ISSN (Online): 2319-7064}

Index Copernicus Value (2013): 6.14 | Impact Factor (2014): 5.611

recovery carries prices to a level higher than the one registered in the previous advance and the subsequent decline halts above the level recorded in the earlier reaction.

\section{Charting}

Charting is the basic tool in technical analysis, which provides visual assistance in defecting changing pattern of price behaviour. The technical analyst is sometimes called the Chartist because of importance of this tool. The Chartists believe that stock prices move in fairly persistent trends. There is an inbuilt inertia, the price movement continues along a certain path(up, down or sideways) until it meets an opposing force due to demand-supply changes. Chartists also believe that generally volume and trend go hand in hand. When a major ,up ${ }^{\text {ee }}$ trend begins, the volume of trading increases and also the price and vice-versa.

The essence of Chartism is the belief that share prices trace out patterns over time. These are a reflection of investor behaviour and it can be assumed that history tends to repeat itself in the stock market. A certain pattern of activity that in the past produced certain results is likely to give rise to the same outcome should it reappear in the future. The various types of commonly used charts are:
a) Line Chart
b) Bar Chart
c) Point and figure Chart

Line Charts: The simplest form of chart is a line chart. Line charts are simple graphs drawn by plotting the closing price of the stock on a given day and connecting the points thus plotted over a period of time. Line charts take no notice of the highs and lows of stock prices for each period.

Table 1: Example of Bull Market Trend

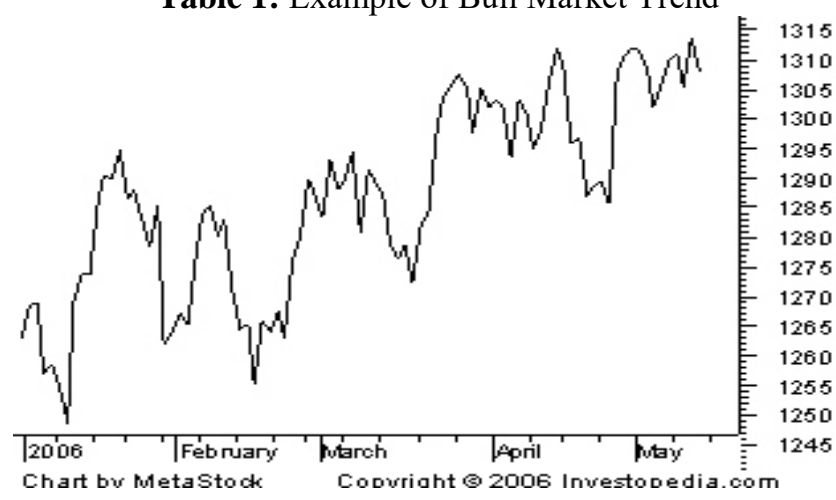

Bar Charts: It is a simple charting technique. In this chart, prices are indicated on the vertical axis and the time on horizontal axis. The market or price movement for a given session (usually a day) is represented on one line. The vertical part of the line shows the high and low prices at which the stock traded or the market moved. A short horizontal tick on the vertical line indicates the price or level at which the stock or market closed.
Table 2: Example of Bear Market Trend

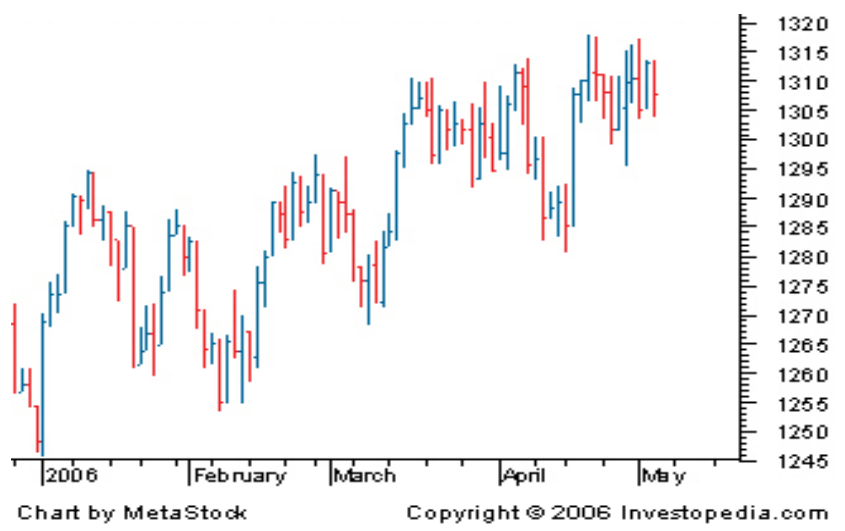

Point and Figure Chart (PFC): Though the point and figure chart is not as commonly used as the other two charts, it differs from the others in concept and construction. In PFC there is no time scale and only price movements are plotted. As a share price rises, a vertical column of crosses is plotted. When it falls, a circle is plotted in the next column and this is continued downward while the price continues to fall. When it rises again, a new vertical line of crosses is plotted in the next column and so on. A point and figure chart that changes column on every price reversal is cumbersome and many show a reversal only for price changes of three units or more (a unit of plot may be a price change of say one rupee).

Table 3: Example of Point Figure Chart (PFC)

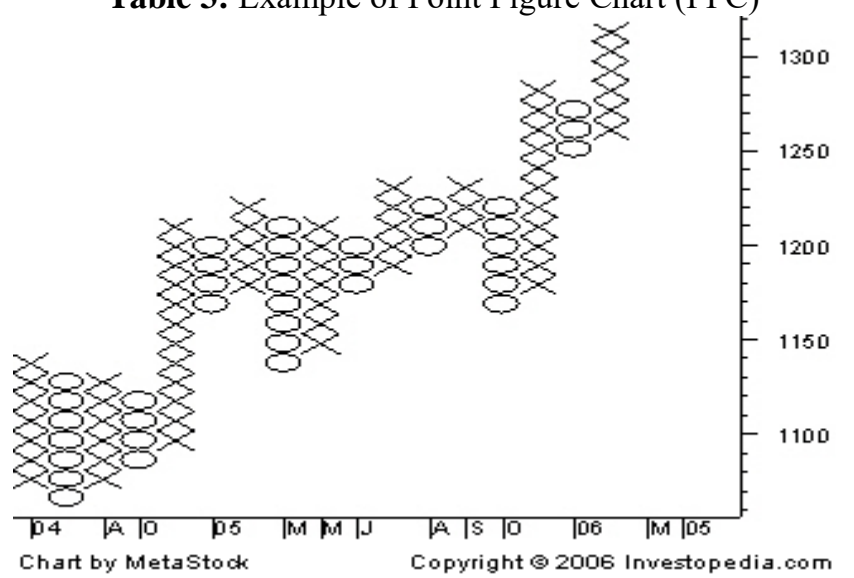

\section{Trends}

A trend can be defined as the direction in which the market is moving. Up trend is the upward movement and downtrend is the downward movement of stock prices or of the market as measured by an average or index over a period of time, usually longer than six months. Trendlines are lines that are drawn to identify such trends and extend them into the future. These lines typically connect the peaks of advances and bottoms of declines. Sometimes, an intermediate trend that extends horizontally is seen. 


\section{International Journal of Science and Research (IJSR) \\ ISSN (Online): 2319-7064}

Index Copernicus Value (2013): 6.14 | Impact Factor (2014): 5.611

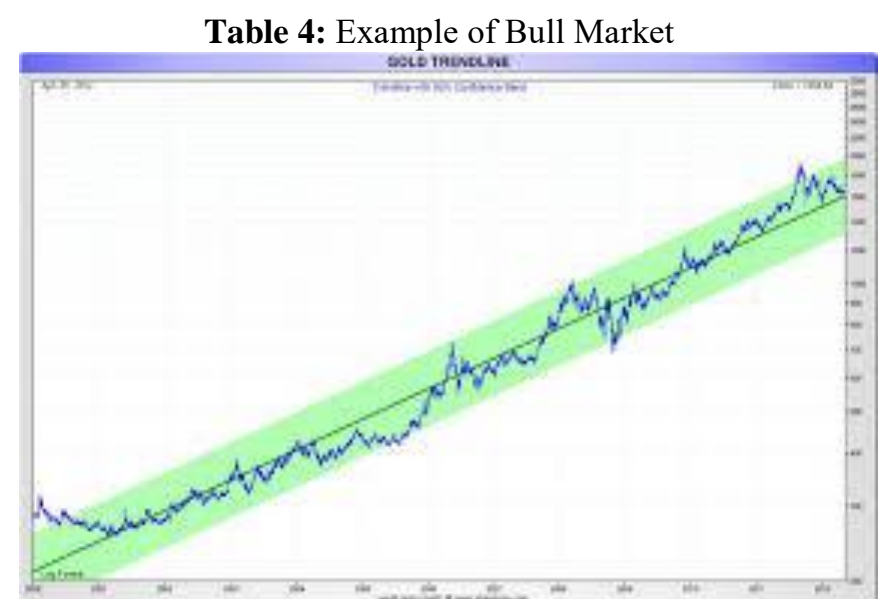

Table 5: Example of Bear Market

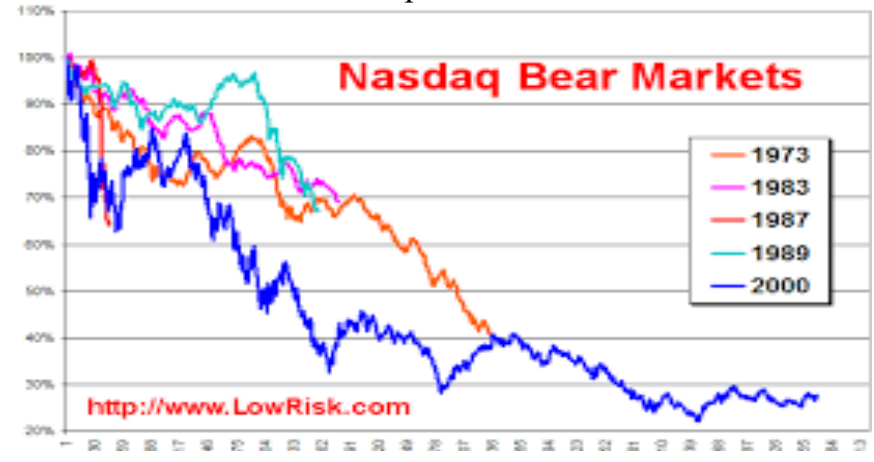

Sideway Trend

A sideway trend is characterized by stock prices trading in a range where successive peaks occur at the same level and successive troughs occur at the same level. The two levels create parallel trend lines. During this time the investor should be extra careful and wait for more definite indicators of the future market movement.

\section{Moving Average Analysis}

Generally, there are two kinds of technical indicators. One type (including moving averages) is best-suited to track an upward or downward trend. The other (including oscillators) is most useful in tracking sideway movements. Among the trend-following indicators, the best-known is the moving average, which charts the average price of stocks over a period of time. With each new calculation, the oldest observation used in figuring the average is dropped and the most recent is substituted. Thus, a ten-day moving average would be calculated using prices from the past 10 days.

Generally, analysts use 2-3 moving averages to signal when to buy or sell. Then they watch closely to see when the averages begin to cross one another. They can also build moving-average envelopes around prices by adding and subtracting a fixed percentage of the average to itself by, putting 'bands' of a percentage point above and below a yday moving average. In case a daily price moves out of the band and hence out of the envelope might be interpreted as meaning that the market is headed for an extreme.

\section{Relative Strength}

The empirical evidence shows that certain securities perform better than other securities in a given market environment and this behaviour remains constant over time. Relative strength is the technical name given to such securities by the technical analysts because these securities have stability and are able to withstand both depression and peak periods. Investors should invest in such securities, because these have constant strength in the market. The relative strength analysis may be applied to individual securities or to whole industries or portfolios consisting of stock and bonds.

The relative strength can be calculated by:

1) Measuring the rate of return of securities

2) Classifying securities

3) Finding out the high average return of securities

4) Using the technique of ratio analysis to find out the strength of an individual security.

Technical analysts measure relative strength as an indication for finding out the return of securities. They have observed that those securities displaying greatest relative strength in good markets (bull) also show the greatest weakness in bad markets (bear). These securities will rise and fall faster than the market. Technical analysts explain relative strength as a relationship between risk and return of a security following the trends in the economy. After preparing charts from different securities over a length of time, the technician would select certain securities which showed relative strength to be the most promising investment opportunities.

\section{Resistance and Support Levels}

The peak price of the stock is called the resistance area. Resistance level is the price level to which the stock or market rises and then falls repeatedly. This occurs during an uptrend or a side way trend. It is a price level to which the market advances repeatedly but cannot breakthrough. At this level, selling increases which causes the price fall. Support level shows the previous low price of the stock. It is a price level to which a stock or market price falls or bottom out repeatedly and then bounce up again. Demand for the stock increases as the price approaches a support level. The buying pressure or the demand supports the price of stock preventing it from going lower.

\section{Break-Out Theory}

Break out is also called as ,confirmation“. This is indicated by drawing a line, which is a period of consolidation, when the share prices move sideways within a range of about $5 \%$ of the share price. Eventually a break out will occur and it is often suggested that the longer the period of consolidation, the greater will be the extent of ultimate rise or fall.

\section{Head and Shoulders Pattern}

The Head and Shoulders pattern is by far the most reliable and widely used of all reversal patterns. This pattern indicates a reversal of an uptrend. This pattern occurs at the end of a bull market and is characterized by two smaller advances flanking a higher advances just as the head lies in between two shoulders.

In reality, the shoulders are not always symmetrical. This does not in any way alter the signals provided by the pattern. The important requirement is that the shoulders should be at lower levels than the head. The left shoulder is seen during the time when there is a lull in the trading market followed by heavy purchases. The quiet time in trading called lull is 


\section{International Journal of Science and Research (IJSR) \\ ISSN (Online): 2319-7064}

Index Copernicus Value (2013): 6.14 | Impact Factor (2014): 5.611

such to raise the price by pushing to a new peak. The head faces with the time when there are heavy purchases in the market that it raises it and then it falls back to indicate that it is far below the top of the left shoulder. The right shoulder indicates that the price rises moderately by the activity in the market but it does not rise in such a manner that it reaches higher than the top of the head while it is reaching top, it begins to fall again and such a decline is indicated. The formation is easily discernible once the right shoulder is formed. The line that joins the points from where the final advance begins and ends is called the neckline. A trend reversal almost always occurs when the neckline is penetrated by the price line. The head and shoulders pattern may be formed over short period of a few weeks or taken even years to emerge. This pattern is the most reliable indicator of the onset of a bear market. The method also provides scope for measuring the extent of fall in prices. The prices are expected to decline after the penetration of the neckline by the price line, at least as much as the distance between the head and the neckline.

Table 8: Example of Head and Shoulder Pattern

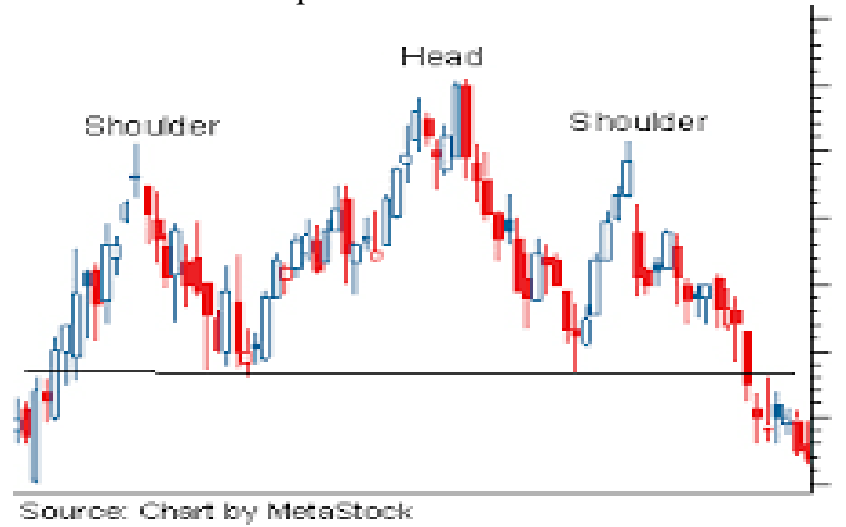

\section{Double Top Formation}

The double top occurs as an uptrend is about to reverse itself. A double top is formed when prices reach the previous high and react immediately, the two highs reached being almost at the same level. Two peaks at comparable heights are seen, with a reaction forming a valley between them. The prices breakout into a bearish phase, once they penetrate the neckline drawn across the bottom of the intervening reaction. The measuring implication is similar as for the head and shoulder formation. If the price line falls below the neckline by a distance equal to the distance between the peak and the trough the indication is to sell. Volume is found to be distinctly low at the second top.

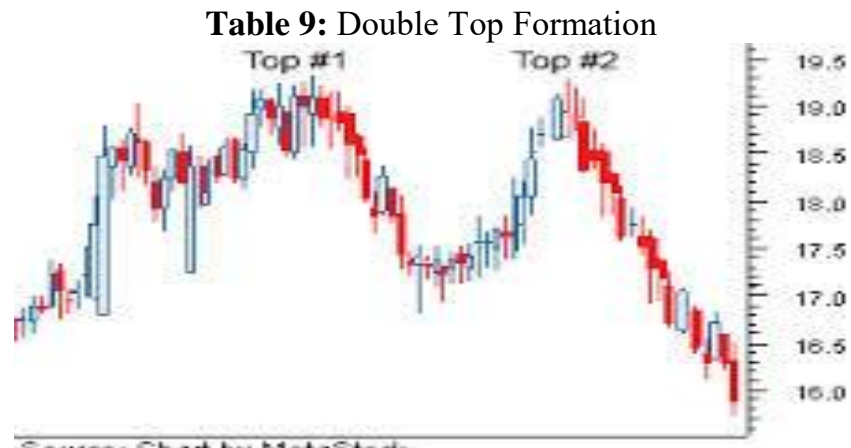

\section{Double Bottom Formation}

A double bottom pattern is just the reverse of a double top and occurs at the end of a downtrend in prices. In double bottom, the second decline is supported by substantially more volume, indicating the price about to rise. The following figure shows the double bottom formation: Sometimes, the tops and bottoms are not found exactly at equal levels, but still these provide valid reversal signals. Sometimes the patterns extend to triple tops or triple bottoms. It must be remembered that longer it takes for the second top (bottom) to appear and deeper the intervening valley (peak) more reliable will be the reversal.

Table 10: Double Bottom formation

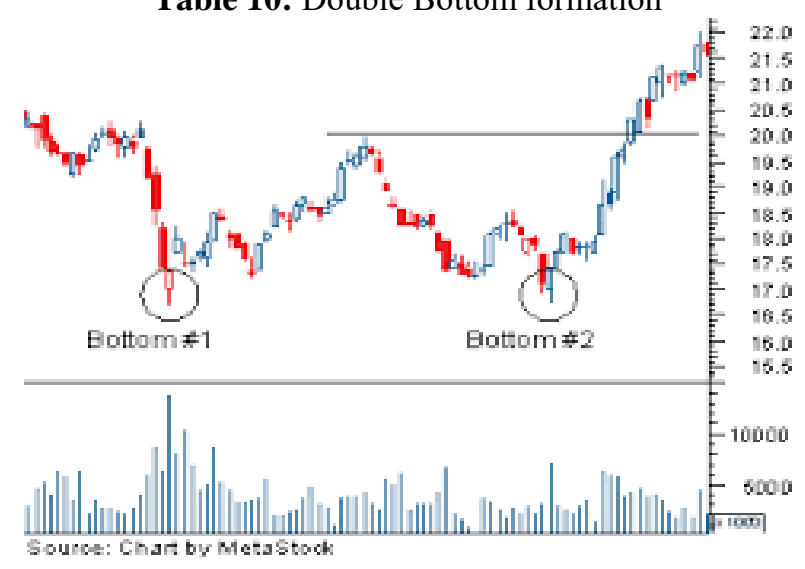

\section{Conclusion}

Investment is a financial activity that involves risk. It is the commitment of funds for a return expected to be realised in the future. Investments may be made in financial assets or physical assets. In either case there is the prospect that the actual return may vary from the expected return. That possibility is the risk involved in the investment. Risk and Return are the two most important characteristics of any investment. Safety and liquidity are also important for an investor. The objective of an investor is specified as maximisation of return and minimisation of risk. The investors in the financial market have different attitudes towards risk and varying levels of risk bearing capacity. Some investors are risk averse, while some may have an affinity to risk. The risk bearing capacity of an investor, on the other hand, is a function of his income. A person with higher income is assumed to have a higher risk bearing capacity. Each investor tries to maximise his welfare by choosing the optimum combination of risk and return in accordance with his preference and capacity. It is highly important for the investor to do both fundamental and technical analysis for deciding the appropriate stock.

\section{References}

[1] V.A Avadhani (2011) "Security Analysis and Portfolio Management" Himalaya Publishing House, New Delhi.

[2] Frank J. Fabozzi, Harry M. Markowitz (2011) "The Theory and Practice of Investment Management" Wiley

[3] Harry Markowitz, Kenneth Blay (2013) "Risk-Return Analysis" McGraw - Hill 


\section{International Journal of Science and Research (IJSR) \\ ISSN (Online): 2319-7064}

Index Copernicus Value (2013): 6.14 | Impact Factor (2014): 5.611

[4] Prasanna Chandra (2012) "Investment Analysis and Portfolio Management" Himalaya Publishing House, Delhi.

[5] Preeti Singh (2014) "Fundamentals of Investment Management" Himalaya Publishing House New Delhi

[6] http://www.investopedia.com

[7] http://www.nasdaq.com/quotes/stock-charts.aspx 